\title{
Motives of sport spectators in China: A case study of the Chinese super league
}

\author{
Chengcheng Wang ${ }^{1}$, Hirotaka Matsuoka ${ }^{2}$ \\ ${ }^{1}$ Graduate School of Sport Sciences, Waseda University \\ ${ }^{2}$ Faculty of Sport Sciences, Waseda University
}

The main purposes of this study were to develop a Motives of Sport Spectator Scale for Chinese professional football (CSL) and to explore the characteristics of CSL spectators. Based on the results of a focus group and a comprehensive literature review, a 12-motive, 38-item scale was developed. Questionnaires were distributed among CSL spectators in Shanghai. The 333 usable questionnaires were divided into two groups, and two confirmatory factor analyses were conducted to validate the scale. Finally, a 9-motive, 24-item scale was confirmed. The adequate Cronbach's alpha coefficients (from .60 for interest in player to .88 for family bonding), AVE values (.43 .70), RMSEA (.072) and CFI (.900) indicated that the new scale was reliable and valid. Further, the results indicated that sport interest, achievement, and socialization were the most important motives for CSL spectators, while, support the city, family bonding and interest in player were the least important motives. Male spectators were more interested in football than female spectators were, attended more games, and were more willing to attend future games. Similar to previous studies, female spectators were more motivated by individual players. The results of the multiple liner regression showed that achievement could explain $30.8 \%$ of the dependent variable of intention for future attendance. Suggestions and implications for sport managers and marketers are given. 